\title{
Aspirin triggered lipid mediators: novel inhibitors of leucocyte trafficking
}

\author{
Charles N Serhan, Clary B Clish
}

\author{
Center for \\ Experimental \\ Therapeutics and \\ Reperfusion Injury, \\ Department of \\ Anesthesiology, \\ Perioperative and Pain \\ Medicine, Brigham \\ and Women's Hospital, \\ Harvard Medical \\ School, Boston, \\ Massachusetts 02115, \\ USA \\ C N Serhan \\ C B Clish \\ Correspondence to: \\ Dr C N Serhan \\ cnserhan@ \\ zeus.bwh.harvard.edu
}

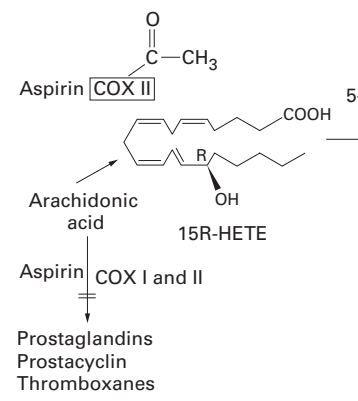

Despite nearly 100 years of wide usage, complete knowledge of the therapeutic impact of aspirin is still evolving ${ }^{1-3}$ and new beneficial effects are being uncovered in cardiovascular disease and cancer. ${ }^{45}$ The irreversible acetylation of cyclo-oxygenase (COX)-1 and its more recently discovered isoform COX $-2^{16}$ with inhibition of prostaglandins is well appreciated and explains some, but not all, of the pharmacological actions of aspirin.

Another series of bioactive lipid mediators on which aspirin has an impact are lipoxins (LX), and their C15 epimers (15R), denoted aspirin triggered lipoxins (ATL, fig 1), which are biosynthesised by separate routes involving transcellular circuits. ${ }^{7}$ Native LX in the nanomolar range inhibit the adhesion and transmigration of polymorphonuclear leucocytes $(\mathrm{PMNs})^{8-10}$ and hence serve as counterregulatory signals operative in the resolution of inflammatory sites. ${ }^{11}{ }^{12}$ Not only do LX serve counter-regulatory roles, but specific enantiomerically modified LX (ATL) may also be actual effectors of well established antiinflammatory therapeutic actions of aspirin. The impact of 5S,6R,15S-trihydroxy-7,9,13trans-11-cis-eicosatetraenoic acid $\left(\mathrm{LXA}_{4}\right)$ and ATL was investigated in tumour necrosis factor $(\mathrm{TNF} \alpha)$ initiated $\mathrm{PMN}$ responses in vitro and in vivo using the metabolically more stable $\mathrm{LX}$ analogues 15R/S-methyl-LXA ${ }_{4}$ and 15-epi-16(parafluoro)-phenoxy-LXA ${ }_{4}$. These compounds represent subtle modifications to the native $\mathrm{LXA}_{4}$ and ATL structure that prevent rapid metabolic inactivation of the lipoxin and 15-epi-LX structures. ${ }^{13} 14$ These compounds are also potent novel inhibitors of TNFa driven PMN associated inflammatory events in vitro as well as in vivo, as shown in a murine model with end points relevant to pulmonary inflammation.

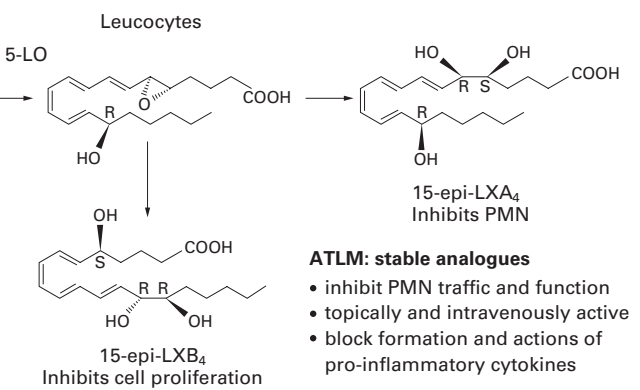

Figure 1 Generation of aspirin triggered lipid mediators (ATLM): anti-inflammation signals. Arachidonic acid can be transformed via COX-1 or its inducible isoform COX-2 to produce prostaglandins and thromboxane. Acetylation by aspirin blocks this conversion. ${ }^{16}$ The lipoxins $(L X)$ are biosynthesised through transcellular interactions and production of 15-epi-LX is triggered when COX-2 is acetylated by aspirin. LX and aspirin triggered lipoxins $(A T L)$ have potent inhibitory actions since their longer acting stable analogues are potent in vivo ${ }^{13} 14$ and appear to be involved in healing/resolution and anti-inflammation.

\section{Methods}

Six day air pouches were raised on the dorsum of 6-8 week old male $\mathrm{BALB} / \mathrm{c}$ mice by subcutaneous injection of $3 \mathrm{ml}$ sterile air and experiments were conducted on day $6 .^{13-15}$ Individual air pouches were injected with either vehicle alone $(0.1 \%$ ethanol), $\mathrm{TNF} \alpha$, ATL stable analogue, or $\mathrm{TNF} \alpha+$ ATL, with each suspended in $1 \mathrm{ml}$ of endotoxin free phosphate buffered saline (PBS; pH 7.45) immediately before injection into pouch cavities. Mice were sacrificed and individual air pouches were lavaged, and the cell exudates were measured and analysed for cytokines/chemokines. ${ }^{13}$

\section{Results}

PMNs express and release several cytokines among which interleukin (IL)-1 $\beta$ is a potent proinflammatory agent. ${ }^{16}$ We have recently investigated the actions of native $\mathrm{LXA}_{4}$ and its stable analogues on $\mathrm{TNF} \alpha$ induced IL- $1 \beta$ release. ${ }^{13}$ PMNs from healthy donors were exposed to increasing concentrations of $15 \mathrm{R} / \mathrm{S}$ methyl- $\mathrm{LXA}_{4}$ or native $\mathrm{LXA}_{4}$ in the presence of $\mathrm{TNF} \alpha$ (25 000-50 000 activity units $/ \mathrm{ml}$ ) or vehicle alone. At a concentration of $100 \mathrm{nM}$, 15R/S-methyl-LXA 4 inhibited approximately $60 \%$ of IL- $1 \beta$ release, a value which is comparable to that obtained with native $\mathrm{LXA}_{4}$. Inhibition of IL- $1 \beta$ by $\mathrm{LXA}_{4}$ and its stable analogue was, at least in part, the result of a downregulation in gene expression, since the IL-1 $\beta$ messenger RNA levels in cells treated with $\mathrm{TNF} \alpha(10 \mathrm{ng} / \mathrm{ml})$ plus $15 \mathrm{R} / \mathrm{S}$-methyl-LXA $(100 \mathrm{nM})$ were decreased by approximately $60 \%$ compared with cells treated with $\mathrm{TNF} \alpha$ alone. $^{13}$ Since IL- $1 \beta$ and $\mathrm{TNF} \alpha$ are two cytokines considered to be important in inflammation, the inhibition of IL- $1 \beta$ suggested that ATL might exert an in vivo anti-cytokine action.

$\mathrm{TNF} \alpha$ evokes leucocyte infiltration in a chemokine-dependent fashion in the murine six day air pouch. ${ }^{15}$ We therefore evaluated the impact of ATL stable analogues 15R/S-methyl$\mathrm{LXA}_{4}$ and 15-epi-16-(para-fluoro)-phenoxy$\mathrm{LXA}_{4}$ in this model to determine whether they also intersect the cytokine/chemokine axis in vivo and inhibit leucocyte infiltration. ${ }^{13} 14$ Murine $\mathrm{TNF} \alpha$ gives a transient infiltration of leucocytes to the pouch cavity in a timedependent fashion with maximal accumulation at four hours. ${ }^{13} 15 \mathrm{R} / \mathrm{S}-m e t h y l-\mathrm{LXA}_{4}$ at a concentration of $25 \mathrm{nmol}$ inhibited the $\mathrm{TNF} \alpha$ stimulated recruitment of leucocytes by approximately $62 \%$. Inhibition was evident at one hour and was maximal at 2-4 hours. At these intervals a reduction in leucocyte infiltration of more than $60 \%$ was noted that remained significantly reduced at eight hours. Inflamma- 


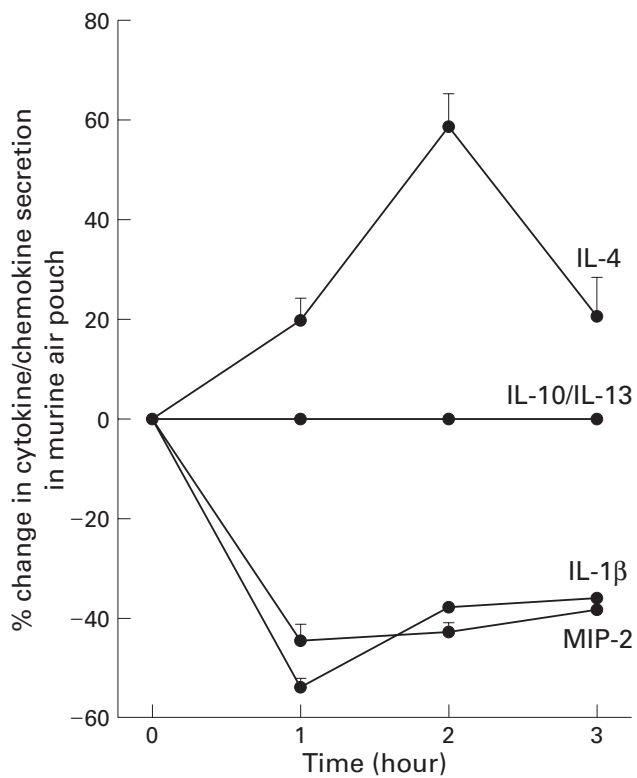

Figure $2 \quad 15 R / S$-methyl-LXA $A_{4}$ redirects the TNFa induced cytokine/chemokine profile in vivo. Sterile PBS $(\sim 1 \mathrm{ml})$ containing either $0.1 \%$ ethanol, TNFa, $15 R / S-m e t h y l-L X A_{4}$ or TNFa $+15 R / S$-methyl-LXA was injected into the pouches and individual lavage exudates were collected at the indicated time periods. Measurements were performed with air pouch cell-free lavage exudates as described by Hachicha et al. ${ }^{13}$ The results are expressed as the \% change compared with the quantities of cytokines found in TNFa injected air pouches in the absence of $L X A_{4}$ (mean (SE) from three different mice for each time interval). Changes in IL-1 $\beta, M I P-2$, and $I L-4$ secretion were statistically significant at all tested time intervals $(p<0.01)$. At one hour the air pouches injected with TNFa alone generated 384 (12) pg $M I P-2 /$ pouch and 14.9 (2.3) pg IL-1B/pouch. $15 \mathrm{R} / \mathrm{S}$-methyl-LXA $\mathrm{A}_{4}$ alone generated 42.7 (0.7) pg IL-4/pouch.

tory exudates were collected four hours after injections and trafficking of cell types into the cavity was measured. In the six day pouches given $\mathrm{TNF} \alpha, \mathrm{PMN}$ constituted the major cell type present within the exudates at four hours with a range of $80-85 \%$. Administration of both $15 \mathrm{R} / \mathrm{S}$-methyl-LXA ${ }_{4}$ and TNF $\alpha$ into the six day air pouch cavity inhibited migration of PMNs, eosinophils, and basophils as well as mononuclear cells. ${ }^{13}$ The fluorinated ATL analogue was compared with aspirin in this model and, when injected into the pouch with $\mathrm{TNF} \alpha$, more than $75 \%$ inhibition was achieved with $10 \mu \mathrm{g}$. This analogue also showed increased stability in whole blood (mouse and human) and intravenous administration was as effective as administration into the air pouch (topical). This stable ATL analogue was also about 100 times more potent than aspirin in blocking PMN influx to the pouch. ${ }^{14}$

Since macrophage inflammatory peptide (MIP)-2 is the major chemokine involved in recruiting PMNs to the pouch cavity following injection of $\mathrm{TNF} \alpha,{ }^{15}$ we determined the action of $15 \mathrm{R} / \mathrm{S}$-methyl- $\mathrm{LXA}_{4}$ in this $\mathrm{TNF} \alpha$ induced chemokine-cytokine axis. MIP- 2 and IL- $1 \beta$ are important proinflammatory cytokines, and IL-4, IL-10, and IL-13 possess immunomodulatory properties. Exudates from selected time intervals were collected and cell-free supernatants assessed for the presence of these murine cytokines. $\quad 15 \mathrm{R} / \mathrm{S}$-methyl-LXA $4 \quad(25 \mathrm{nmol})$ inhibited TNF $\alpha$ stimulated MIP-2 and IL-1 $\beta$ release by $48 \%$ and $30 \%$, respectively (fig 2 ). $15 \mathrm{R} / \mathrm{S}$-methyl-LXA $\mathrm{LA}_{4}$ alone in the air pouch did not stimulate MIP-2 or IL-1 $\beta$ release. In sharp contrast, $15 \mathrm{R} / \mathrm{S}-$ methyl-LXA $\mathrm{LA}_{4}$ stimulated the appearance of IL- 4 within the exudates. This stimulation of IL-4 was observed both with and without TNF $\alpha$. Neither IL-10 nor IL-13 was detected within the pouch exudates. These results show that administration of $15 \mathrm{R} / \mathrm{S}$ methyl-LXA 4 dramatically modified the cytokine/chemokine axis in $\mathrm{TNF} \alpha$ initiated acute inflammation and, interestingly, this re-orientation of the cytokine/chemokine axis paralleled the reduction in leucocyte infiltration.

\section{Discussion}

$\mathrm{LXA}_{4}$ and ATL (generated by separate biosynthetic mechanisms in vivo; fig 1 and Serhan et $a l^{10-12}$ ), as evidenced by the actions of the metabolically stable analogue 15R/S-methyl$\mathrm{LXA}_{4}$, are both potent cytokine regulating lipid mediators that can also have an impact on the course of inflammation initiated by TNF $\alpha$. In this exudate and skin wound model, ${ }^{13} 15 \mathrm{R} / \mathrm{S}$ methyl-LXA ${ }_{4}$ not only inhibited TNF $\alpha$ elicited PMNs, monocytes, basophils, and eosinophils as well as the appearance of IL-1 $\beta$ and MIP-2, but also stimulated IL- 4 appearance within the pouch. These results provide the first evidence to indicate that lipoxins and ATL induce upregulation of potential "anti-inflammatory" cytokines such as IL-4. ${ }^{17}$ It is likely that both the inhibition of IL-1 $\beta$ and MIP-2 within exudates and IL-4 levels in the surrounding tissues by metabolically stable LX analogues may represent, in part, some of the in vivo impact of $\mathrm{LXA}_{4}$ and aspirin triggered 15-epi-LXA $\mathrm{LX}_{4}$. These findings provide a new understanding of the relationship between "anti-inflammatory" cytokines and lipid mediators and also open new avenues to investigate protective lipid and protein mediators in host defence.

In summary, these results suggest that $\mathrm{LXA}_{4}$ and aspirin triggered $\mathrm{LXA}_{4}$ appear to be involved in controlling not only acute inflammatory responses, but also mechanisms that can influence chronic inflammatory responses. The recent results reviewed here also support the notion that aspirin may exert its beneficial action in part via the biosynthesis of endogenous ATLMs such as 15 -epi-LXA ${ }_{4}$ that can, in turn, act directly on PMNs as well as affect the appearance of chemokines and cytokines. Thus, LX-ATL can protect host tissues via multi-level regulation of proinflammatory signals and may be relevant new lipid mediators of interest in airway diseases.

These studies were supported in part by National Institutes of Health grant no. GM-38765. CC is an Arthritis Foundation postdoctoral fellow.

1 Vane JR, Bakhle YS, Botting RM. Cyclooxygenases 1 and 2. Anпu Rev Pharmacol Toxicol 1998;38:97-120.

2 Marcus AJ. Aspirin as prophylaxis against colorectal cancer. N Engl f Med 1995;333:656-8.

3 Cronstein BN, Montesinos MC, Weissmann G. Salicylates and sulfasalazine, but not glucocorticoids, inhibit leukocyte accumulation by an adenosine-dependent mechanism that is independent of inhibition of prostaglandin synthesis and p105 of NFкB. Proc Natl Acad Sci USA 1999;96:6377-81. 
4 Ridker PM, Cushman M, Stampfer MJ, et al. Inflammation, aspirin, and the risk of cardiovascular disease in apparently
healthy men. $N$ Engl $\mathcal{F}$ Med 1997;336:973-9.

5 Levy GN. Prostaglandin H synthases, nonsteroidal antiinflammatory drugs, and colon cancer. FASEB $\mathcal{F} 1997 ; 11$ 234-7.

6 Herschman HR. Recent progress in the cellular and molecular biology of prostaglandin synthesis. Trend Cardiovasc Med 1998;8:145-50.

7 Serhan CN, Haeggström JZ, Leslie CC. Lipid mediator networks in cell signaling: update and impact of cytokines. FASEB F 1996;10:1147-58

8 Takano T, Fiore S, Maddox JF, et al. Aspirin-triggered 15-epi-lipoxin $\mathrm{A}_{4}$ and $\mathrm{LXA}_{4}$ stable analogs are potent inhibitors of acute inflammation: evidence for antiinflammatory receptors. F Exp Med 1997;185:1693-704.

9 Clària J, Serhan CN. Aspirin triggers previously undescribed bioactive eicosanoids by human endothelial cell leukocyte interactions. Proc Natl Acad Sci USA 1995;92. 9475-9.

10 Colgan SP, Serhan CN, Parkos CA, et al. Lipoxin A modulates transmigration of human neutrophils across intestinal

11 Serhan CN, Takano T, Gronert $\mathrm{K}$, et al. Lipoxin and aspirin-triggered 15-epi-lipoxin cellular interactions: antiinflammatory lipid mediators. Clin Chem Lab Med 1999;37 299-309.
12 Serhan CN. Lipoxins and aspirin-triggered 15-epi-lipoxins. In: Gallin JI, Snyderman R, eds. Inflammation: basic principles and clinical correlates. Philadelphia: Lippincott Williams \& Wilkins, 1999: 373-85.

13 Hachicha M, Pouliot M, Petasis NA, et al. Lipoxin (LX)A and aspirin-triggered 15-epi-LXA ${ }_{4}$ inhibit tumor necrosis factor $1 \alpha$-initiated neutrophil responses and trafficking: regulators of a cytokine-chemokine axis. $\mathcal{F}$ Exp Med 1999;189:1923-9.

14 Clish CB, O'Brien JA, Gronert K, et al. Local and systemic delivery of a stable aspirin-triggered lipoxin prevents
neutrophil recruitment in vivo. Proc Natl Acad Sci USA 1999;96:8247-52.

15 Tessier PA, Naccache PH, Clark-Lewis I, et al. Chemokine networks in vivo: involvement of $\mathrm{C}-\mathrm{X}-\mathrm{C}$ and $\mathrm{C}-\mathrm{C}$ chemoknes in neutrophil extravasation in vivo in response to TNF- $\alpha$. F Immunol 1997;159:3595-602.

16 Marucha PT, Zeff RA, Kreutzer DL. Cytokine-induced IL-1 $\beta$ gene expression in the human polymorphonuclear leukocyte: transcriptional and post-transcriptional regulation by tumor nom for tion by tumor nect

17 Lehn M, Weiser WY, Engelhorn S, et al. IL-4 inhibits $\mathrm{H}_{2} \mathrm{O}$ production and antileishmanial capacity of human cultured monocytes mediated by IFN- $\gamma$. F Immunol 1989;143:30204 . 